\title{
Characterization of Newly Synthesized Starch Coated Fe/Cu Nanoparticles and its Dechlorination Efficiency on the Low and High Chlorinated Biphenyls ${ }^{1}$
}

\author{
S. Ganesh-Kumar ${ }^{a, b}, *$, K. Kalimuthu ${ }^{a, c}$, and S. R. D. Jebakumar ${ }^{a}$ \\ ${ }^{a}$ Department of Molecular Microbiology, School of Biotechnology, \\ Madurai Kamaraj University, Madurai-625021, Tamil Nadu, India \\ ${ }^{b}$ State Key laboratory of Environmental Aquatic Chemistry, Research Center for Eco-Environmental Sciences, \\ Chinese Academy of Sciences, Beijing-100085, China \\ ${ }^{c}$ Department of Chemical Engineering, University of California, Davis California-95616, USA \\ *e-mail: ganesh_kumarbt@yahoo.co.in \\ Received December 20, 2016
}

\begin{abstract}
New starch coated zero-valent $\mathrm{Fe} / \mathrm{Cu}$ nanoparticles were synthesized by borate reduction method. The surface profile of synthesized nanoparticles was studied by atomic force microscopy (AFM) imaging. Comparison of Infra red (IR) spectra of soluble starch and starch coated $\mathrm{Fe} / \mathrm{Cu}$ nanoparticle revealed the complex formation between $\mathrm{Fe} / \mathrm{Cu}$ nanoparticles and soluble starch. X-ray diffraction pattern and Energydispersive X-ray spectroscopy (EDX) spectrum analysis exposed the composition of starch coated $\mathrm{Fe} / \mathrm{Cu}$ nanoparticles. SEM imaging determined the size of $\mathrm{Fe} / \mathrm{Cu}$ nanoparticle which was fallen into the size of 48 to $70 \mathrm{~nm}$. In this study, the capability of starch coated $\mathrm{Fe} / \mathrm{Cu}$ nanoparticle to degrade the low and high chlorinated biphenyls were studied extensively. It was observed that soluble starch and $\beta$-cyclodextrin have enhanced the polychlorinated biphenyl (PCB) degradation by preventing iron nano-agglomeration and making the PCB as a soluble form, respectively. The dechlorination was further confirmed by the estimation of released chloride ion during the PCB degradation. The present study suggested that this new method could be an efficient and reliable method to treat PCB contaminated soil and sediments.
\end{abstract}

DOI: $10.1134 / \mathrm{S} 2070205117040074$

\section{INTRODUCTION}

Polychlorinated biphenyls (PCBs) are the family of manmade chemicals which contain 209 individual PCB compounds with a various level of toxicity. Their nonflammable and insulating properties have made their use as insulators in transformers and capacitors. However, their persistent nature and toxicity have created public health issues and scientific concern over the several decades. Therefore, it is important to remediate these toxic chemicals to neutralize their toxicity and save the environment. Several methods have been introduced for the remediation of PCBs. For the past two decades, zero-valent iron nanoparticles have widely been used to treat various halogenated aromatic and aliphatic contaminants including polychlorinated biphenyls [13, 18, 21]. Zero-valent iron nanoparticle (nZVI) remediates the PCBs through surface reaction process, called reductive dechlorination [25]. The bare zero-valent iron nanoparticle is composed of a zero-valent metallic iron core and ferrous(II) oxide layer. The application of zero-valent

\footnotetext{
${ }^{1}$ The article is published in the original.
}

iron nanoparticle to remediate $\mathrm{PCBs}$ is primarily relied on its electron-donating properties [20]. Under the ambient conditions, nZVI is fairly reactive in water and the process of dechlorination by nZVI can be represented as given below,

$$
\begin{gathered}
2 \mathrm{Fe}^{0} \rightarrow 2 \mathrm{Fe}^{2+}+4 \mathrm{e}^{-} \\
3 \mathrm{H}_{2} \mathrm{O} \rightarrow 3 \mathrm{H}^{+}+3 \mathrm{OH}^{-} \\
2 \mathrm{H}^{+}+2 \mathrm{e}^{-} \rightarrow \mathrm{H}_{2}(\mathrm{~g}) \\
\mathrm{RCl}+\mathrm{H}^{+}+2 \mathrm{e}^{-} \rightarrow \mathrm{RH}+\mathrm{Cl}^{-}
\end{gathered}
$$

In recent times, zero-valent iron nanoparticles have been successfully employed to accelerate the dechlorination process in contaminated groundwater and sediments [23]. Furthermore, 'permeable reactive barriers' which composed of zero-valent iron nanoparticles have been applied for the treatment of groundwater contamination $[9,5]$. According to [26], the addition of nZVI particle to the ground water and soil slurry system which induces the growth of the microbial community and thereby degradation process was increased. 
Commercially available zero-valent iron nanoparticles have a relatively low surface area for the dechlorination process [17]. Extensive methods have been reported for the synthesis of ZVI nanoparticles with higher reactivity. For instance, ZVI nanoparticles have been synthesized in the form of bimetallic particles such as $\mathrm{Pd} / \mathrm{Fe}^{0}, \mathrm{Pt} / \mathrm{Fe}^{0}, \mathrm{Ag} / \mathrm{Fe}^{0}$ and $\mathrm{Ni} / \mathrm{Fe}^{0}$ to prevent their rapid oxidation and ensure a higher rate of degradation [2]. This bimetallic system is highly compatible with the treatment of industrial chlorinated effluents $[4,16]$. Zero-valent iron nanoparticles are aggregative in nature. The use of stabilizers prevents the aggregation and increases the surface area of iron nanoparticles, and thereby enhances the overall degradation process [11]. Several chemical compounds have been reported for the stabilization of nZVI. Among those chemicals, soluble starch is widely used as a stabilizing agent. It is highly compatible, eco-friendly and cost effective [7, 12]. Generally, PCBs are mostly insoluble in water (hydrophobic) and getting adsorbed with soil particles. In present days, surface acting agents (surfactants) are used to reduce this adsorption problem during the PCB dechlorination [22]. Cyclodextrin is significantly used to solubilize the hydrophobic compounds to enhance the remediation $[1,15]$.

In the present work, it was aimed to characterize the newly synthesized starch coated $\mathrm{Fe} / \mathrm{Cu}$ nanoparticles and also to apply for dechlorination of PCBs. Synthesized starch coated zero-valent $\mathrm{Fe} / \mathrm{Cu}$ particles were characterized using Atomic force Microscopy (AFM), X-Ray diffraction (XRD) spectroscopy, Fourier transform infrared spectroscopy (FT-IR) and Scanning Electron Microscopy (SEM) and Energydispersive X-ray spectroscopy (EDS or EDX). Subsequently, dechlorination of low and high chlorinated biphenyl was also determined by Gas-liquid chromatography equipped with Flame Ionization Detector (FID). Finally, the release of chloride ion during the dechlorination was estimated.

\section{EXPERIMENTAL}

\subsection{Chemicals}

Analytical grade PCBs mixture (Aroclor 1254), standard PCB congeners (Oekanal grade) such as 4-Chlorobiphenyl (4-CB), 4,4',-Chlorobiphenyl $\left(4,4^{\prime}-\mathrm{CB}\right), 2,4^{\prime}, 5-C h l o r o b i p h e n y l \quad\left(2,4^{\prime}, 5-\mathrm{CB}\right)$ and $\beta$-cyclodextrin were purchased from Sigma-Aldrich, Bangalore, India. Aroclor and PCB congeners had a minimum purify level of 98.8 and $97 \%$, respectively and did not contain biphenyl as an impurity. HPLC grade solvents were used for low and high chlorinated biphenyl extraction studies.

\section{Preparation of Starch Stabilized Fe/Cu Nanoparticles}

Starch coated $\mathrm{Fe} / \mathrm{Cu}$ nanoparticles were prepared by the minor modification of Carboxymethyl cellulose
(CMC) stabilized $\mathrm{Fe} / \mathrm{Cu}$ nanoparticle synthesis [3]. The preparation was carried out in a $250 \mathrm{~mL}$ conical flask with a magnetic bar. Before the preparation, DD water and starch solution were purged with $\mathrm{N}_{2}$ gas for 15-30 min to remove the dissolved oxygen. The concentration of $\mathrm{FeSO}_{4} \cdot 7 \mathrm{H}_{2} \mathrm{O}$ and soluble starch used in this study was $0.21 \mathrm{M}$ and $0.8 \%$, respectively. Sodium borohydride $(0.26 \mathrm{M})$ was added to the iron (II)starch solution with continuous stirring under the nitrogen condition (I). After $15 \mathrm{~min}$ of continuous stirring, $0.02 \mathrm{M}$ of $\mathrm{CuSO}_{4} \cdot 5 \mathrm{H}_{2} 0$ (II) was added and again it was stirred for $15 \mathrm{~min}$. The resultant black precipitate was harvested by centrifugation and washed with thrice the volume of deionized water to get rid of the unwanted trace chemicals. Then it was washed with anhydrous ethanol and dried under nitrogen gas. Finally, the starch coated $\mathrm{Fe} / \mathrm{Cu}$ nanoparticles were stored under the protection of nitrogen gas and used within two hours from the synthesis.

$$
\begin{aligned}
& 3 \mathrm{Fe}\left(\mathrm{H}_{2} \mathrm{O}\right)_{6}^{2+}+3 \mathrm{BH}_{4}^{-}+3 \mathrm{H}_{2} \mathrm{O} \\
& \rightarrow \mathrm{Fe}^{0} \downarrow+3 \mathrm{~B}(\mathrm{OH})_{3}+10.5 \mathrm{H}_{2} . \\
& \mathrm{Cu}^{2+}+\mathrm{Fe}^{0} \rightarrow \mathrm{Cu}^{0} \downarrow+\mathrm{Fe}^{2+} .
\end{aligned}
$$

\section{Physical Characterization of Synthesised Nanoparticle}

Surface pattern and arrangement nature of starch coated $\mathrm{Fe} / \mathrm{Cu}$ nanoparticles were determined by the AFM imaging (Model, APE Research: A100-SGS). Synthesized nZVI was dropped on the small piece of mica plate and it was air dried at room temperature. Imaging of air dried sample (in triplicate) was done at the high resolution of the cantilever. Two dimensional (2D) and three dimensional (3D) images were captured at the selected area. Particle size, shape and appearance of synthesized starch coated $\mathrm{Fe} / \mathrm{Cu}$ nanoparticles were analyzed using SEM imaging (JSM-6390, JEOL, USA). A thin film of the starch coated $\mathrm{Fe} / \mathrm{Cu}$ nanoparticles and uncoated $\mathrm{Fe} / \mathrm{Cu}$ nanoparticles were prepared on a carbon coated copper grid by dropping a very small amount of the sample. The film on SEM grid was dried under the vacuum condition for $5 \mathrm{~min}$ and image was captured at selected area.

In order to measure the elemental composition of starch coated $\mathrm{Fe} / \mathrm{Cu}$ nanoparticles, Energy-dispersive $\mathrm{X}$-ray spectroscopy (EDS) analysis was done. A drop of starch coated $\mathrm{Fe} / \mathrm{Cu}$ nanoparticle (in triplicate) was air dried on carbon film and then it was subjected to EDS stage (Oxford Instruments, Model No. 7582). The instrument was equipped with a Thermo EDS attachments and operating at an accelerating voltage of $20 \mathrm{kV}$. The properties and phase purity of synthesized starch coated $\mathrm{Fe} / \mathrm{Cu}$ nanoparticles were determined by the X-ray diffraction (XRD) analysis at ambient temperature. Finally to determine the starch coating on the iron nanoparticle, IR spectrum of starch coated $\mathrm{Fe} / \mathrm{Cu}$ nanoparticle was compared with 
(a)

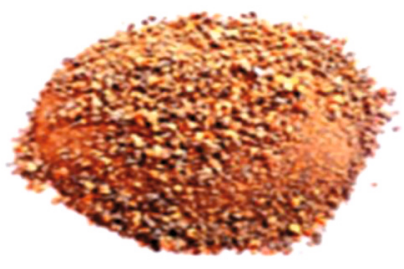

(b)

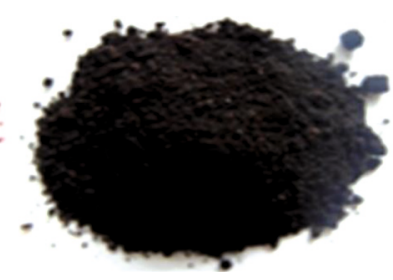

Fig. 1. Picture showing the synthesized iron nanoparticles under ambient condition. Copper uncoated Fe nanoparticles quickly turned into rust form (a). Copper coated Fe nanoparticles $(\mathrm{Fe} / \mathrm{Cu})$ remain stable at aerobic condition $(b)$.

IR spectra of soluble starch alone. The FT-IR (KBr) spectra were analysed using SHIMADZU FT/IR8400S spectrophotometer. IR spectra were measured

in the wave number of 350 to $4500 \mathrm{~cm}^{-1}$ and the spectral resolution was $4 \mathrm{~cm}^{-1}$.

\section{Dechlorination of Low Chlorinated Biphenyls}

Synthesized starch coated $\mathrm{Fe} / \mathrm{Cu}(500 \mathrm{mg} / \mathrm{L})$ nanoparticle was added into the $25 \mathrm{~mL}$ of serum bottles containing deionized water (DI) amended with 4-CB, $4,4^{\prime}-\mathrm{CB}$ and $2,4^{\prime}, 5-\mathrm{CB}(500 \mathrm{mg} / \mathrm{L})$. All the experimental serum bottles were tightly closed by Teflon coated aluminum cap. Control bottles (without nanoparticles) and samples bottles (with nanoparticles) were incubated at $25 \pm 1^{\circ} \mathrm{C}$ with $100 \mathrm{rpm}$. After $12 \mathrm{~h}$ of incubation, PCBs were extracted from the incubated bottles using HPLC grade hexane. The PCB degradation rate was estimated by Gas Chromatography equipped with Flame Ionization Detector (GC-FID).

$$
\text { Percentage of Degradation }=100-\frac{\text { GC Peak area of PCB congeners }(\text { sample })}{\text { GC Peak area of PCB congeners }(\text { control })} \times 100 \%
$$

\section{Chloride Ion Estimation}

The release of inorganic chloride ion was estimated during the degradation of 2,4',5- chlorobiphenyl and it measured by ferric thiocyanate method [6]. Synthesized starch coated $\mathrm{Fe} / \mathrm{Cu}(500 \mathrm{mg} / \mathrm{L})$ nanoparticles were incubated on the chloride free solution containing 4-CB, 4, 4'-CB and 2,4',5-CB $(500 \mathrm{mg} / \mathrm{L})$. After the incubation, $\mathrm{Fe} / \mathrm{Cu}$ nanoparticles were removed by centrifugation (8000 rpm, $5 \mathrm{~min}$ ) and the supernatant was used for chloride estimation. Chloride ion was estimated at $460 \mathrm{~nm}$ using the standard curve of sodium chloride $(0.05-1.5 \mathrm{mM}) .1 \mathrm{ml}$ of incubated suspension, $0.2 \mathrm{~mL}$ of iron reagent and $0.4 \mathrm{~mL}$ of thiocyanate reagent were used to quantify the chloride ion. The solution was makeup to $2 \mathrm{~mL}$ with the addition of chloride free DD. $\mathrm{H}_{2} \mathrm{O}$.

\section{Dechlorination of High Chlorinated Biphenyls}

High chlorinated biphenyls in Aroclor 1254 such as $2,3,4,5,2^{\prime}, 3^{\prime}, \quad 2,3,4,5,2^{\prime}, 4^{\prime}, 6^{\prime}, \quad 2,3,4,2^{\prime}, 3^{\prime}, 4^{\prime}$, $2,4,5,3^{\prime}, 4^{\prime}, 5^{\prime}, \quad 2,3,4,5,2^{\prime}, 3^{\prime}, 6^{\prime}, \quad 2,3,5,6,2^{\prime}, 3^{\prime}, 4^{\prime}$, $2,3,4,5,3^{\prime}, 4^{\prime}, \quad 2,3,4,5,2^{\prime}, 3^{\prime}, 5^{\prime}, \quad 2,3,4,5,2^{\prime}, 4^{\prime}, 5^{\prime} \quad$ and $2,3,4,5,2^{\prime}, 3^{\prime}, 4^{\prime}-\mathrm{CB}$ were subjected into the degradation studies. Degradation studies were carried out by starch coated $\mathrm{Fe} / \mathrm{Cu}$ nanoparticles in the presence and absence of $\beta$-cyclodextrin (surfactant). Synthesized starch coated $\mathrm{Fe} / \mathrm{Cu}$ nanoparticles $(500 \mathrm{mg} / \mathrm{L})$ were added to the solution containing aroclor- $1254(50 \mathrm{mg} / \mathrm{L})$ and incubated at $25 \pm 1{ }^{\circ} \mathrm{C}$ with $100 \mathrm{rpm}$. After $46 \mathrm{~h}$ of incubation, $\mathrm{PCB}$ congeners were extracted from the incubated bottles (in triplicate) and the degraded PCB rate was estimated.

\section{RESULTS AND DISCUSSION}

\subsection{Synthesis of Starch Coated Fe/Cu Nanoparticles}

New starch coated $\mathrm{Fe} / \mathrm{Cu}$ nanoparticles were synthesized in the presence of nitrogen gas at $28^{\circ} \mathrm{C}$. Synthesized $\mathrm{Fe} / \mathrm{Cu}$ nanoparticles were easily deposited due to the aggregative nature. But after the addition of soluble starch, $\mathrm{Fe} / \mathrm{Cu}$ nanoparticles were not observed by aggregation. Even after $48 \mathrm{~h}$ of synthesis, it was not precipitated and remained evenly suspended in solution. Synthesized bimetallic $\mathrm{Fe} / \mathrm{Cu}$ nanoparticles were more stable than the copper uncoated Fe nanoparticles (Fig. 1b). Copper uncoated Fe nanoparticles were immediately turned into the brown colored rust (Fig. 1a). It is believed that copper could promote the dechlorination by preventing the formation of iron oxides. The addition of metal onto the iron surface can reduce the oxidation of iron, thus maintaining the reactivity of the zero-valent iron nanoparticles (23). As compared to other reported bimetallic nanoparticles such as $\mathrm{Pd} / \mathrm{Fe}, \mathrm{Pt} / \mathrm{Fe}, \mathrm{Ag} / \mathrm{Fe}$ and $\mathrm{Ni} / \mathrm{Fe}^{0}, \mathrm{Fe} / \mathrm{Cu}$ nanoparticle is safe and cheaper in the environmental application.

\subsection{Characterization Synthesized Iron Nanoparticle}

Generally, zero-valent iron nanoparticles are more magnetic in nature. The magnetic force operates between the iron particles may affect the dispersion stability. This magnetic force of nZVI particle also influences the dechlorination by reducing the nano surface area to PCB [19]. In the present study, soluble starch has been used to reduce the magnetic aggregation problem. Aggregation was not observed among the starch coated $\mathrm{Fe} / \mathrm{Cu}$ nanoparticles. It revealed by SEM and AFM image analysis. AFM imaging was 


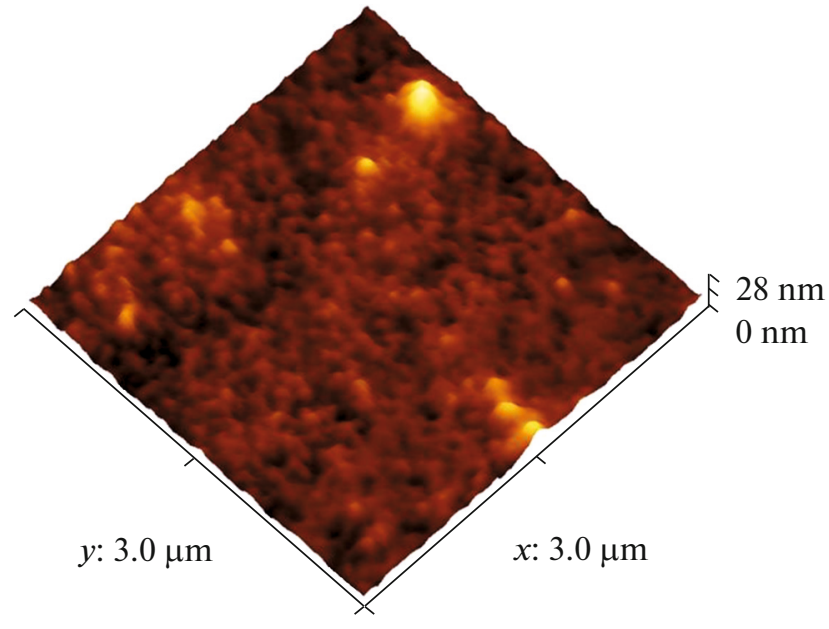

Fig. 2. Picture showing the three dimensional AFM image of starch coated $\mathrm{Fe} / \mathrm{Cu}$ nanoparticle. It reveals the uniform distribution of synthesized nanoparticles.

revealed the topology of starch coated $\mathrm{Fe} / \mathrm{Cu}$ nanoparticle by a uniform distribution. The sample image showed the well distributed individual particles with the height of $0-28 \mathrm{~nm}$. In the top-view image, all particles appear highly symmetrical (Fig. 2). From
SEM imaging, the starch uncoated $\mathrm{Fe} / \mathrm{Cu}$ nanoparticles appeared as clumps, which reveals its aggregative nature. Aggregation of iron nanoparticles makes them into unshaped and their size was measured in micron. In the case of starch coated $\mathrm{Fe} / \mathrm{Cu}$ nanoparticles, the nanoparticles observed as distinct particles by $48-70 \mathrm{~nm}$ in size without any aggregation (Fig. 3). Both results suggested that the soluble starch is potentially preventing the aggregation and made the uniform distribution of starch coated $\mathrm{Fe} / \mathrm{Cu}$ nanoparticles. Figure 4a shows the EDX spectrum of spherical structured starch coated $\mathrm{Fe} / \mathrm{Cu}$ nanoparticles. Elemental composition of starch coated $\mathrm{Fe} / \mathrm{Cu}$ nanoparticle was found to be iron, copper, oxide, sodium and sulphate. The peak observed at 0.5 and $6.5 \mathrm{keV}$ indicates the presence of iron. Likewise, the peaks observed at 1,8 and $8.9 \mathrm{keV}$ indicates the presence of copper.

Starch coated $\mathrm{Fe} / \mathrm{Cu}$ particles were subjected to XRD analysis and the result is showed in Fig. 4b. The diffractive intensive peaks were obtained at the range of $10^{\circ}$ to $80^{\circ}$ of 2 theta positions. The diffraction pattern of starch coated $\mathrm{Fe} / \mathrm{Cu}$ particle showed two intensive peaks at $19.2^{\circ}$ and $44^{\circ}$ of the 2 theta positions. This diffraction pattern was compared with available data in JCPDS database (Joint Committee on powder diffraction standards database). Accordingly, the
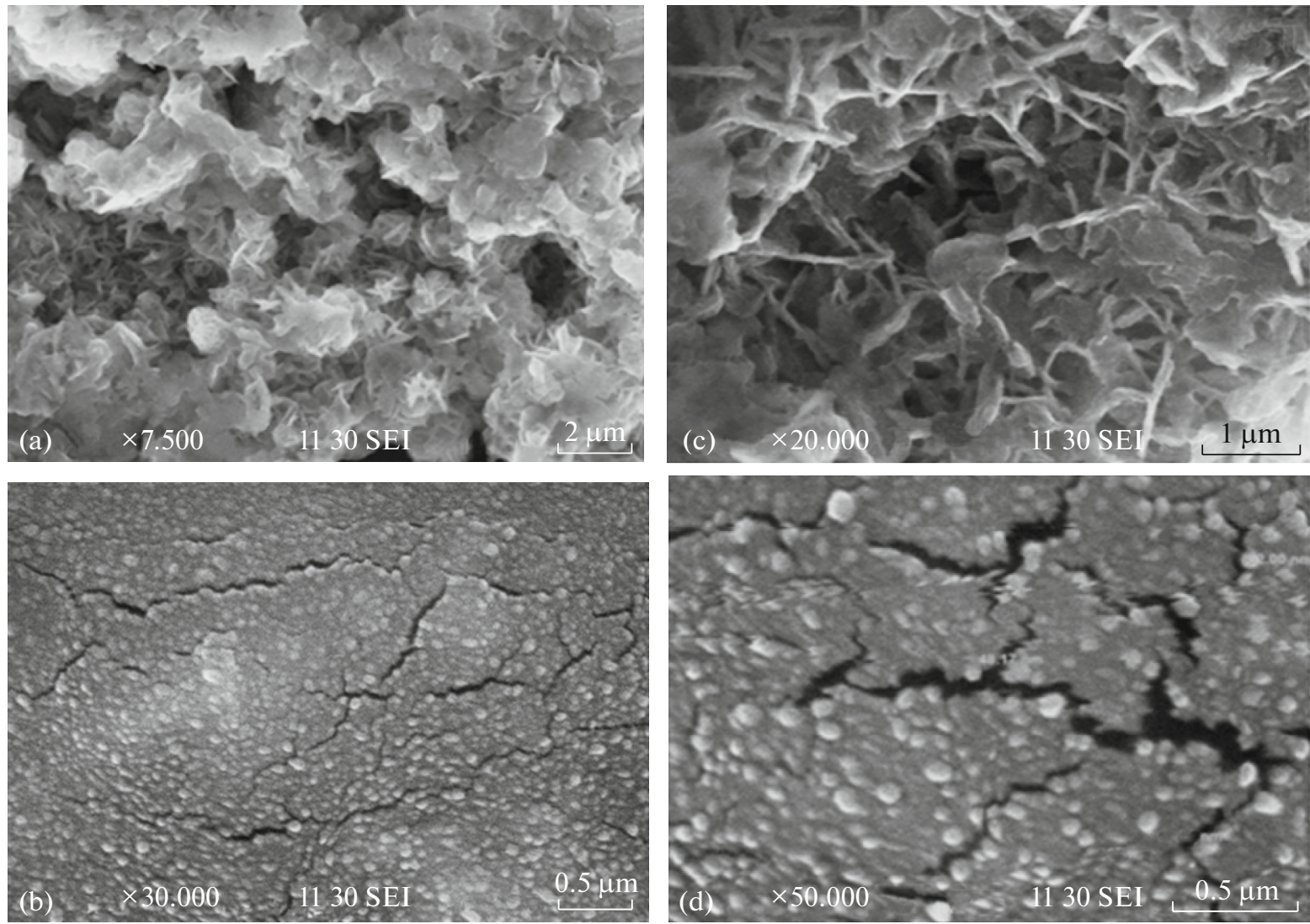

Fig. 3. SEM images showing the appearance of starch uncoated $\mathrm{Fe} / \mathrm{Cu}$ nanoparticles (a and b) and starch coated $\mathrm{Fe} / \mathrm{Cu}$ nanoparticles under different magnifications (c and d). 
(a)

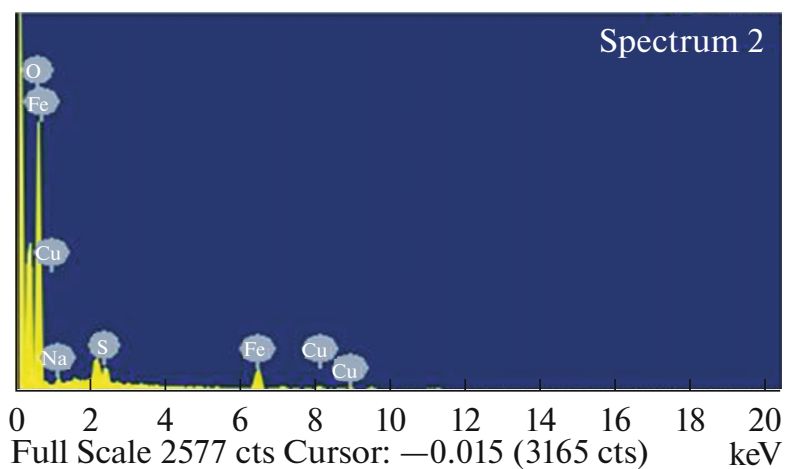

(b)

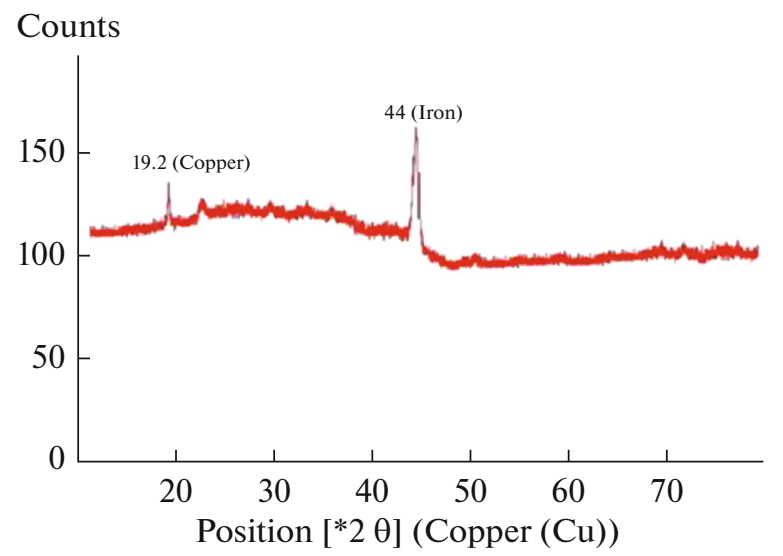

Fig. 4. Energy-dispersive X-ray spectroscopy (EDX) spectrum indicating the elemental composition of starch coated Fe/Cu nanoparticle (a). X-Ray diffraction (XRD) pattern of starch coated $\mathrm{Fe} / \mathrm{Cu}$ nanoparticles that reveals the presence of iron and copper metal (b).
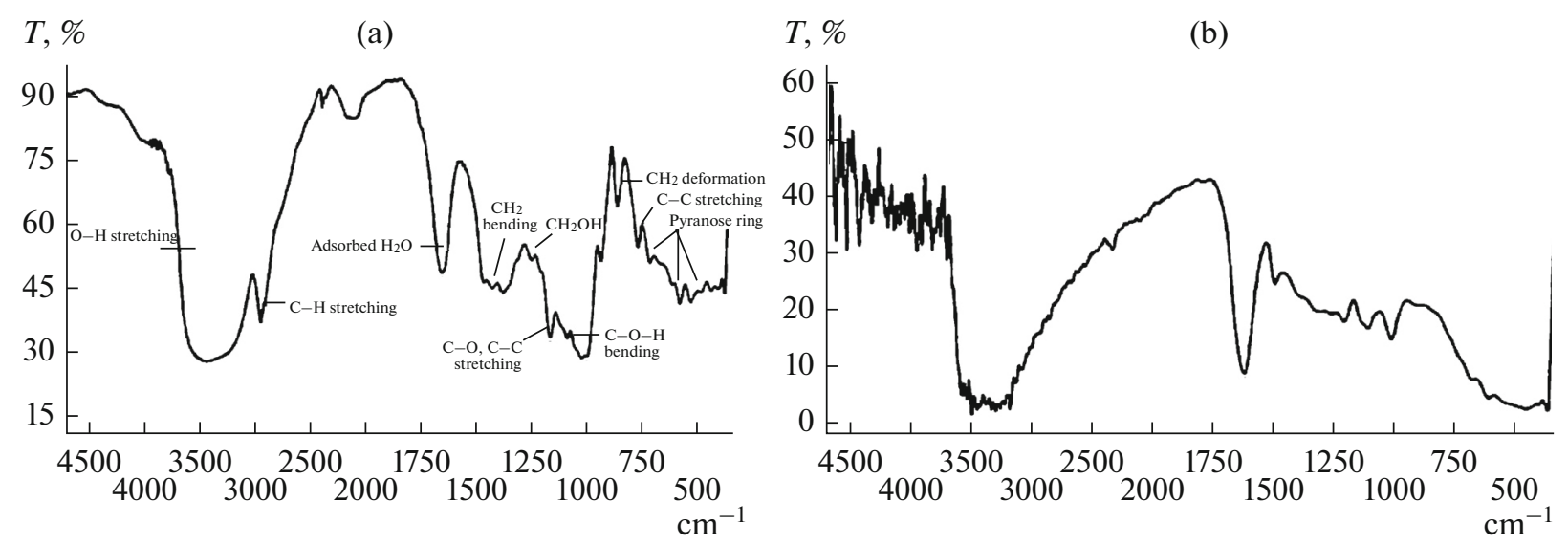

Fig. 5. Infra red (IR) spectrum showing the various functional groups of soluble starch (a) and starch coated Fe/Cu nanoparticles (b).

recorded peaks at $19.2^{\circ}$ and $44^{\circ}$ were matched with copper and iron, respectively. The protein diffraction file (PDF) reference number of copper and iron were 01-1242 and 85-1410, respectively.

The FT-IR spectrum of starch coated $\mathrm{Fe} / \mathrm{Cu}$ nanoparticles showed various bands, stretches and bends within 350 and $4600 \mathrm{~cm}^{-1}$. There were some band vibrations or shifting in the spectrum of starch coated $\mathrm{Fe} / \mathrm{Cu}$ nanoparticles (Fig. 5b). Major shifting or vibration was found at $240-1213 \mathrm{~cm}^{-1}\left(\mathrm{CH}_{2} \mathrm{OH}\right.$ group), 1159-1213 $\mathrm{cm}^{-1}$ (C-O and $\mathrm{C}-\mathrm{C}$ group), 2900-3200 $\mathrm{cm}^{-1}$ (C-H group). These band shifts suggested that complex formation occurred between $\mathrm{Fe} / \mathrm{Cu}$ nanoparticles and soluble starch. Comparison of the FT-IR spectra of soluble starch and starch coated $\mathrm{Fe} / \mathrm{Cu}$ nanoparticles confirmed the complex formation between the iron nanoparticles and soluble starch. Formation of intra-starch iron clusters plays a fundamental role in dispersion and the stabilization of zero-valent iron nanoparticles [8, 11]. During the iron nanoparticle synthesis, hydroxyl groups of starch facilitate the complex formation between ferric ions and the soluble starch. After the addition of strong reducing agent sodium borate $\left(\mathrm{NaBH}_{4}\right), \mathrm{Fe}^{3+}$ ions reduced into the $\mathrm{Fe}^{0}$ particles. When iron nano clusters $\left(\mathrm{Fe}^{0}\right)$ are formed in the starch matrix, the hydroxyl groups of the soluble starch act as a passivating agent, thereby preventing the resultant nanoparticles from agglomeration [10].

\subsection{Dechlorination of Low Chlorinated Biphenyls}

After $12 \mathrm{~h}$ of incubation, starch coated $\mathrm{Fe} / \mathrm{Cu}$ nanoparticles were completely degraded the 4-CB, 4,4',-CB and 2,4',5-CB (Fig. 6a). The experimental bottles in the absence of nZVI (control) were not showed any degradation. The degraded low chlorinated biphenyls were determined using the GC chro- 
(a)

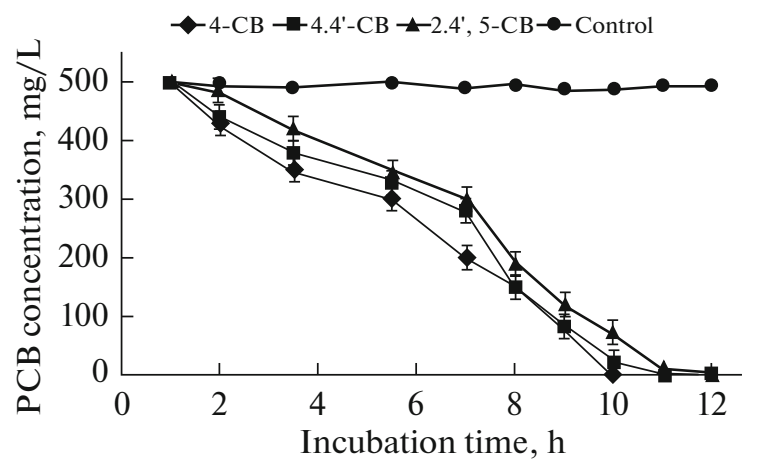

(b)

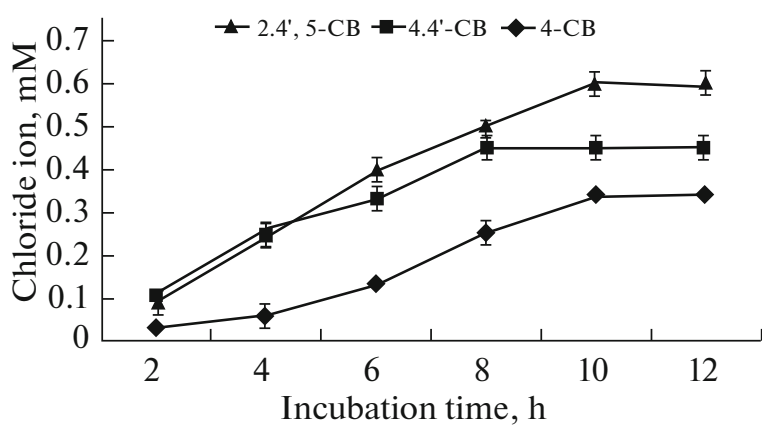

Fig. 6. Degradation of low chlorinated biphenyls by starch coated $\mathrm{Fe} / \mathrm{Cu}$ nanoparticles (a). Release of chloride ion during the process of dechlorination by starch coated Fe/Cu nanoparticles (4-chlorobiphenyl (4-CB), 4,4',-chlorobiphenyl (4,4'-CB), 2,4',5-chlorobiphenyl $\left(2,4^{\prime}, 5-\mathrm{CB}\right)(\mathrm{b})$.

matogram peak area of control and sample. The previous degradation studies were carried out in the experimental solution containing solvents such as methanol and ethanol etc [17, 24]. In this study, synthesized starch coated $\mathrm{Fe} / \mathrm{Cu}$ nanoparticles were stable at experimental deionized water without by making any solvent solution. But experimental bottles were closed with Teflon coated aluminum cap to reduce the spontaneous evaporation of PCB.

\subsection{Estimation of Chloride Ion During PCB Degradation}

The release of chloride ion was estimated during the dechlorination of 4-CB, 4,4'-CB and 2,4',5-CB. The amount of released chloride ion was 0.01 to $0.45 \mathrm{mM}$ and the process of dechlorination was com- pleted within 8 to $10 \mathrm{~h}$ of incubation (Fig. $6 \mathrm{~b}$ ). The chloride ion release was not observed in the tubes without the addition of $\mathrm{Fe} / \mathrm{Cu}$ nanoparticles (control bottles). It is proved that iron nanoparticle released the chloride ion one by one into the medium by reductive dechlorination. In this evidences, iron nanoparticles act as an electron donor in the presence of water and PCB act as an electron acceptor. After the reductive dechlorination process, polychlorinated biphenyl turned into the dechlorinated or detoxified form [14].

\subsection{Dechlorination of High Chlorinated Biphenyls}

The ability of starch coated $\mathrm{Fe} / \mathrm{Cu}$ nanoparticle to degrade the low and high chlorinated biphenyls in commercial PCBs mixture (Aroclor 1254) were determined using Gas Chromatography equipped with

Degradation of high chlorinated biphenyls by synthesized starch coated $\mathrm{Fe} / \mathrm{Cu}$ nanoparticle

\begin{tabular}{|c|c|c|c|c|c|}
\hline \multirow[b]{2}{*}{$R T, \min$} & \multirow[b]{2}{*}{ Peak no. } & \multirow[b]{2}{*}{ PCB Congeners } & \multirow{2}{*}{$\begin{array}{l}\text { Molecular } \\
\text { formula }\end{array}$} & \multicolumn{2}{|c|}{ Degradation*, \% } \\
\hline & & & & $\begin{array}{c}\text { without } \\
\beta \text {-cyclodextrin }\end{array}$ & $\begin{array}{c}\text { with } \\
\beta \text {-cyclodextrin }\end{array}$ \\
\hline 38.02 & 1 & $2,3,4,5,2^{\prime}, 3^{\prime}$ & $\mathrm{C}_{12} \mathrm{H}_{4} \mathrm{Cl}_{6}$ & $95 \pm 1.5$ & 100 \\
\hline 39.58 & 2 & $2,3,4,5,2^{\prime}, 4^{\prime}, 6^{\prime} ; 2,3,5,6,2^{\prime}, 4^{\prime}, 5^{\prime}$ & $\mathrm{C}_{12} \mathrm{H}_{5} \mathrm{Cl}_{6}$ or $\mathrm{C}_{12} \mathrm{H}_{4} \mathrm{Cl}_{7}$ & $70.16 \pm 2.5$ & 100 \\
\hline 50.09 & 3 & $2,3,4,2^{\prime}, 3^{\prime}, 4^{\prime}$ & $\mathrm{C}_{12} \mathrm{H}_{4} \mathrm{Cl}_{6}$ & $90.64 \pm 1.6$ & 100 \\
\hline 52.25 & 4 & $2,4,5,3^{\prime}, 4^{\prime}, 5^{\prime}$ & $\mathrm{C}_{12} \mathrm{H}_{4} \mathrm{Cl}_{6}$ & $68.15 \pm 3.4$ & 100 \\
\hline 53.19 & 5 & $2,3,4,5,2^{\prime}, 3^{\prime}, 6^{\prime} ; 2,3,4,5,2^{\prime}, 4^{\prime}$ & $\mathrm{C}_{12} \mathrm{H}_{3} \mathrm{Cl}_{7}$ or $\mathrm{C}_{12} \mathrm{H}_{4} \mathrm{Cl}_{6}$ & 100 & 100 \\
\hline 58.49 & 6 & $2,3,5,6,2^{\prime}, 3^{\prime}, 4^{\prime}$ & $\mathrm{C}_{12} \mathrm{H}_{3} \mathrm{Cl}_{7}$ & 100 & 100 \\
\hline 59.82 & 7 & $2,3,4,5,3^{\prime}, 4^{\prime} ; 2,3,4,6,2^{\prime}, 3^{\prime}, 4^{\prime}$ & $\mathrm{C}_{12} \mathrm{H}_{3} \mathrm{Cl}_{7}$ or $\mathrm{C}_{12} \mathrm{H}_{4} \mathrm{Cl}_{6}$ & $9 \pm 2.1$ & 100 \\
\hline 62.78 & 8 & $2,3,4,5,2^{\prime}, 3^{\prime}, 5^{\prime}$ & $\mathrm{C}_{12} \mathrm{H}_{3} \mathrm{Cl}_{7}$ & $90.24 \pm 2.2$ & 100 \\
\hline 63.25 & 9 & $2,3,4,5,2^{\prime}, 4^{\prime}, 5^{\prime}$ & $\mathrm{C}_{12} \mathrm{H}_{3} \mathrm{Cl}_{7}$ & $16 \pm 2.5$ & 100 \\
\hline 64.84 & 10 & $2,3,4,5,2^{\prime}, 3^{\prime}, 4^{\prime}$ & $\mathrm{C}_{12} \mathrm{H}_{3} \mathrm{Cl}_{7}$ & $95.64 \pm 1.8$ & 100 \\
\hline
\end{tabular}

*Percent degradation was calculated by direct comparison with the control (Heat Killed Cells). Values shown are mean \pm SD for three experiments. 
(a)
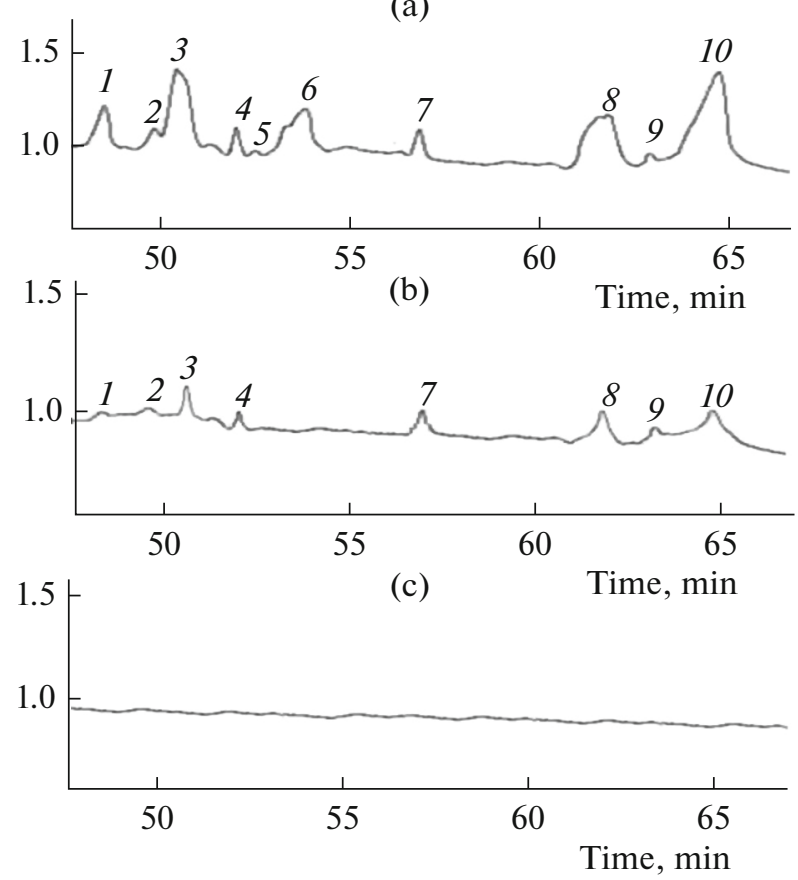

Fig. 7. GC chromatogram of high chlorinated biphenyls in PCBs mixture (Aroclor 1254) that incubated in absence of $\mathrm{Fe} / \mathrm{Cu}$ nanoparticles and $\beta$-Cyclodextin (control) (a). Aroclor 1254 incubated with $\mathrm{Fe} / \mathrm{Cu}$ nanoparticles (b), Aroclor 1254 incubated with $\mathrm{Fe} / \mathrm{Cu}$ nanoparticles and $\beta$-cyclodextin (c). Arrow symbol indicates the degraded PCB congeners after $46 \mathrm{~h}$ of incubation.

FID. Figure 8 showing the 10 different peaks of hexa and penta chlorinated biphenyls after $46 \mathrm{~h}$ of incubation. Most of the high chlorinated PCB congeners such as 2,3,4,5,2',3', 2,3,4,5,2',4',6', 2,3,4,2',3',4', $2,4,5,3^{\prime}, 4^{\prime}, 5^{\prime}, \quad 2,3,4,5,2^{\prime}, 3^{\prime}, 6^{\prime}, \quad 2,3,5,6,2^{\prime}, 3^{\prime}, 4^{\prime}$, $2,3,4,5,2^{\prime}, 3^{\prime}, 5^{\prime}$ and $2,3,4,5,2^{\prime}, 3^{\prime}, 4^{\prime}$-chlorobiphenyls were significantly degraded, but not completely degraded by starch coated $\mathrm{Fe} / \mathrm{Cu}$ nanoparticles without $\beta$-Cyclodextrin (Fig. $7 \mathrm{~b}$, table). In particular, $2,3,4,5,3^{\prime}, 4^{\prime}$ and $2,3,4,5,2^{\prime}, 4^{\prime}, 5^{\prime}$ were not significantly degraded. However, at the same time, all of the PCB congeners were degraded completely by starch coated $\mathrm{Fe} / \mathrm{Cu}$ nanoparticles with the addition of $\beta$-cyclodextrin (Fig. 8c). It revealed that $\beta$-Cyclodextrin accelerates PCB degradation by enhancing the solubility of PCB mixture and reducing the surface tension [1]. In the previous report, PCB dechlorination was demonstrated within $72 \mathrm{~h}$ of incubation in an ethanol-water mixture under ambient conditions by zero-valent iron nanoparticles [23]. In the present study, high chlorinated biphenyls were successfully dechlorinated within $46 \mathrm{~h}$ of incubation with starch coated $\mathrm{Fe} / \mathrm{Cu}$ nanoparticles. Starch coated $\mathrm{Fe} / \mathrm{Cu}$ nanoparticles efficiently degraded the low and high chlorinated biphenyls in commercial PCBs mixture, when compared to the starch uncoated $\mathrm{Fe} / \mathrm{Cu}$ nanoparticles (result not shown). It indicated that the usage of solu- ble starch not only prevents aggregation of iron nanoparticles and also it enhances the overall dechlorination effectiveness due to the greater specific surface area of finer nanoparticles.

\section{CONCLUSIONS}

New starch coated zero-valent $\mathrm{Fe} / \mathrm{Cu}$ nanoparticles were synthesized and characterized by various analytical methods. The capability of synthesized starch coated $\mathrm{Fe} / \mathrm{Cu}$ nanoparticle to degrade the toxic polychlorinated biphenyls was observed. From this study, it was determined that iron nano-agglomeration was controlled by the starch coating on zero-valent $\mathrm{Fe} / \mathrm{Cu}$ nanoparticles. From the results of batch works reveals that $\beta$-cyclodextrin could enhance the PCB degradation by making PCB as a soluble form. The dechlorination was further confirmed by the release of chloride ion during the degradation process. Unlike other bimetallic iron nanoparticle, it is cheap, reliable and toxic free method. Lifetime of this synthesized $\mathrm{Fe} / \mathrm{Cu}$ nanoparticles are higher and effective than other bimetallic iron nanoparticles. Further field trial studies have to be done regarding these observations.

\section{ACKNOWLEDGMENTS}

This research paper is dedicated to the late Professor RD. Jebakumar Solomon. This work has financially supported by the 'Council of Scientific and Industrial Research-Human resource Development group' (CSIR-HRDG) and the 'Department of Biotechnology' (DBT), India, and we gratefully thanked. Also we thank Miss J. Mohanapriya for her preparation work on manuscript.

\section{REFERENCES}

1. Bai, G., Brusseau, M.L., and Miller, R.L., Appl. Environ. Microbiol., 1997, vol. 63, p. 1866.

2. Biswas, P. and Wu, C.Y., J. Air Waste Manage. Assoc., 2005, vol. 55 , p. 708.

3. Cao, J., Xu, R., Tang, H., et al., Sci. Total Environ., 2011, vol. 409, p. 2336.

4. Cirwertny, D.M., Bransford, S.J., and Roberts, A.L., Environ. Sci. Technol., 2007, vol. 41, p. 3734.

5. Clark, C.J., Rao, P.S.C., and Annable, M.D., J. Hazard. Mater., 2003, vol. 96, p. 65.

6. Coleman, N.V., Mattes, T.E., Gossett, J.M., et al., Appl. Environ. Microbiol., 2002, vol. 68, p. 2726.

7. Cundy, A.B., Hopkinson, L., and Whitby, R.L.D., Sci. Total Environ., 2008, vol. 400, p. 42.

8. Dragunski, D.C. and Pawlicka, A., Mater. Res., 2001, vol. 4 , p. 77.

9. Gusmao, A.D., Campos, T.M.P., Nobre, M.M.M., et al., J. Hazard. Mater., 2004, vol. 110, p. 105.

10. He, F. and Zhao, D., Environ. Sci. Technol., 2005, vol. 39 , p. 3314. 
11. He, F. and Zhao, D.Y., Appl. Catal., B, 2008, vol. 84, p. 533.

12. Henn, K. and Waddill, D.W., Rem. J., 2006, vol. 16, p. 57.

13. Kim, Y.H. and Carraway, E.R., Environ. Sci. Technol., 2000, vol. 34, p. 2014.

14. Li, L., Fan, M., Brown, R.C., et al., Crit. Rev. Environ. Sci. Technol., 2006, vol. 36, p. 405.

15. Lien, H.L., Elliott, D.S., Sun, Y.P., et al., J. Environ. Eng. Manage., 2006, vol. 16, p. 71.

16. Lin, C.J., Liou, Y.H., and Lo, S.L., Chemosphere, 2009, vol. 74, p. 314.

17. Lowry, G.V. and Johnson, K.M., Environ. Sci. Technol., 2004, vol. 38, p. 5208.

18. Miehr, R., Tratnyek, P.G., Bandstra, J.Z., et al., Environ. Sci. Technol., 2004, vol. 38, p. 139.
19. Phenrat, T., Saleh, N., Sirk, K., et al., Environ. Sci. Technol., 2007, vol. 41, p. 284.

20. Stumm, W. and Morgan, J.J., Aquatic Chemistry: Chemical Equilibria and Rates in Natural Waters, New York: Wiley, 1996.

21. Tee, Y.H., Grulke, E., and Bhattacharyya, D., Ind. Eng. Chem. Res., 2005, vol. 44, p. 7062.

22. Volkering, F., Breure, A.M., and Rulkens, W.H., Biodegradation, 1998, vol. 8, p. 401.

23. Wang, C.B. and Zhang, W.X., Environ. Sci. Technol., 1997, vol. 31, p. 2154.

24. Xu, J. and Bhattacharyya, D., Ind. Eng. Chem. Res., 2007, vol. 46, p. 2348.

25. Xu, Y. and Zhang, W.X., Ind. Eng. Chem. Res., 2000, vol. 39 , p. 2238

26. Elliott, D.W. and Zhang, W.X., Environ. Sci. Technol., 2001 , vol. 35 , no. 24 , pp. $4922-4926$. 